\title{
Relação do ácido linoleico e alfa linolênico na alimentação de aves de postura: Uma revisão
}

\author{
Linoleic acid and alpha linolenic acid ratio in poultry feed: A review \\ Relación entre el ácido linoleico y el ácido alfa linolénico em las dietas de las aves de corral: Una \\ revisión
}

Recebido: 19/07/2021 | Revisado: 25/07/2021 | Aceito: 27/07/2021 | Publicado: 04/08/2021

\author{
Letícia Aline Lima da Silva \\ ORCID: https://orcid.org/0000-0002-4758-9890 \\ Universidade Estadual de Maringá, Brasil \\ E-mail: leticiaalinezoo@gmail.com \\ Vitor Magalhães de Mendonça Cunha Miranda \\ ORCID: https://orcid.org/0000-0001-7473-4398 \\ Universidade Estadual de Maringá, Brasil \\ E-mail: vitor.zootec01@gmail.com \\ José Matheus de Moura Andrade \\ ORCID: https://orcid.org/0000-0001-5469-5942 \\ Universidade de São Paulo, Brasil \\ E-mail: josematheus@usp.br \\ Tatiana Carlesso dos Santos \\ ORCID: https://orcid.org/0000-0003-1463-7785 \\ Universidade Estadual de Maringá, Brasil \\ E-mail: tcsantos@uem.br
}

\begin{abstract}
Resumo
O uso de lipídios na alimentação das aves é uma estratégia nutricional muito utilizada, pois contribui com o incremento energético, fornece importantes nutrientes para um equilíbrio nutricional e é a principal fonte de ácidos graxos poliinsaturados. Os poliinsaturados compreende as famílias de ácidos graxos ômega-3 e ômega-6. Onde seus principais representantes são os ácidos linoléico, alfa-linolênico, ácidos araquidônico e docosaexaenoico. Esses ácidos vêm sendo bastante estudados devido a suas diversas funções no organismo da ave reprodutora como: melhoria da qualidade do pintinho, enriquecimento do ovo, função anti-inflamatória, diminuição da gordura entre outros. Devido a esses benefícios vem se buscando o enriquecimento dos ovos com esses ácidos através da manipulação da dieta. Para isso tem sido utilizada diversas fontes lipídicas ricas em PUFAs n-3 como a linhaça, canola e óleos de peixes. O objetivo dessa revisão é abordar o efeito de diferentes relações do ácido linoleico (18:2 n-6) e alfa linolênico (18:3 n-3) na alimentação de aves de postura. A metodologia utilizada foi um estudo descritivo, baseada em artigos científicos publicados, resultando assim em um compilado de dados para essa revisão bibliográfica.
\end{abstract}

Palavras-chave: Codornas japonesas; Matrizes de frango de corte; Ômega 3; Ômega 6.

\begin{abstract}
The use of lipids in poultry feed is a widely used nutritional strategy because it contributes to the energy increment, provides important nutrients for nutritional balance, and is the main source of polyunsaturated fatty acids. The polyunsaturated fatty acids comprise the families of omega- 3 and omega- 6 fatty acids. Where their main representatives are the linoleic, alpha-linolenic, arachidonic, and docosahexaenoic acids. These acids have been widely studied due to their various functions in the body of breeding birds, such as the improvement of the chick quality, egg enrichment, anti-inflammatory function, fat reduction, among others. Due to these benefits, the enrichment of eggs with these acids has been sought through the manipulation of the diet. For this, several lipidic sources rich in n-3 PUFAs have been used, such as flaxseed, canola, and fish oils. This review aims to address the effect of different ratios of linoleic acid (18:2 n-6) and alpha linolenic acid (18:3n-3) in the diet of laying birds. The methodology used was a descriptive study, based on published scientific articles, thus resulting in a data compilation for this literature review.
\end{abstract}

Keywords: Quail japanese; Broiler breeder; Omega-3; Omega-6.

\section{Resumen}

El uso de lípidos en la alimentación de las aves de corral es una estrategia nutricional muy utilizada, ya que contribuye al incremento energético, aporta nutrientes importantes para el equilibrio nutricional y es la principal fuente de ácidos grasos poliinsaturados. Los ácidos grasos poliinsaturados comprenden las familias de los ácidos grasos omega-3 y 
omega-6. Sus principales representantes son el ácido linoleico, el ácido alfa-linolénico, el ácido araquidónico y el ácido docosahexaenoico. Estos ácidos han sido ampliamente estudiados debido a sus diversas funciones en el organismo del ave de cría como: mejora de la calidad del polluelo, enriquecimiento del huevo, función antiinflamatoria, reducción de la grasa entre otras. Debido a estos beneficios, se ha buscado el enriquecimiento de los huevos con estos ácidos mediante la manipulación de la dieta. Para ello, se han utilizado varias fuentes lipídicas ricas en PUFAs n-3, como los aceites de linaza, canola y pescado. El objetivo de esta revisión es abordar el efecto de las diferentes proporciones de ácido linoleico (18:2 n-6) y ácido alfa linolénico (18:3 n-3) en la alimentación de las aves de corral. La metodología utilizada fue un estudio descriptivo, basado en artículos científicos publicados, lo que dio como resultado una recopilación de datos para esta revisión bibliográfica.

Palabras clave: Codornices japonesas; Reproductoras de polos; Omega-3; Omega-6.

\section{Introdução}

A ingestão de lipídios pelas matrizes de codornas apresenta grande importância, além de suprir as necessidades energéticas são utilizadas para atender as exigências de ácidos graxos essenciais e a absorção das vitaminas lipossolúveis. Os ácidos graxos essenciais são importantes para o crescimento, desenvolvimento e reprodução dos animais. Porém, as aves são incapazes de sintetizar os ácidos linoleicos (ômega-6) e linolênicos (ômega-3), que são considerados essenciais, por isso, devem ser fornecidos na dieta para a adequada nutrição dos animais e a produção com qualidade

O ácido linolênico (LNA) pertencente à família do ômega-3 é precursora dos ácidos graxos de cadeia longa, como o ácido eicosapentaenoico (EPA) e o docosahexaenoico ácido (DHA). Já o ácido linoleico (LA) está na família do ômega-6 e é precursor do ácido araquidônico (AA). As principais fontes desses ácidos são os óleos, como por exemplo, os óleos de soja e linhaça que são ricos em n-6 e n-3, respectivamente, são bastante utilizados na alimentação de aves (Dessimoni \& Aguiar, 2021).

Esses ácidos graxos afetam a reprodução e a eclodibilidade que são segmentos cruciais na produção avícola, principalmente em relação aos ovos incubáveis e a taxa de nascimento. Na nutrição de matrizes são alternativos para melhorar esses parâmetros, pois quando presentes na dieta serão depositados na gema, melhorando assim o metabolismo, permitindo alta eclodibilidade e pintinhos melhores (Cherian \& Sim, 1997). Porém, a dieta das aves comerciais é baseada em milho e farelo de soja, que são esses ricos em n-6, tendo baixo teor de n-3 na composição, esse desbalanço na relação n-6:n-3 influencia negativamente sobre as taxas de reprodução dos animais (Cherian \& Sim, 1997).

A busca por adequadas relações n6:n3 na alimentação de aves poedeiras tem sido bastante estudadas, devido seus efeitos no enriquecimento dos ovos e na reprodução. Uma das maneiras de melhorar essa relação é o aumento de ômega 3 na dieta, dentre as fontes que mais são utilizadas estão óleo de linhaça e peixe. Na literatura já possuem trabalhos que abordam quais as melhores relações para matrizes de frango de corte e postura, entretanto para codornas não se têm tantos trabalhos utilizando essas relações. Portanto, essa revisão foi feita com o objetivo de abordar o efeito de diferentes relações do ácido linoleico (18:2 n-6) e alfa linolênico (18:3 n-3) na alimentação de aves poedeiras.

\section{Metodologia}

Para essa revisão foi realizada uma pesquisa qualitativa segundo Pereira et al. (2018), os artigos escolhidos foram retirados de diferentes bases de dados: Scielo, periódicos Capes, Elsevier, Google Scholar, Pubmed, Science Direct e Scopus. Com recorte temporal de 1992 a 2021.

Os artigos foram classificados utilizando como tema principal relação do Ácido Linoleico e Alfa Linolênico na alimentação de aves de postura, como enfoque em enriquecimento de ovos e nutrição do embrião. Tendo como palavras chaves: relação LA:LNA, ômega 3, ômega 6 , ovos, incubação e reprodução. Como critério de seleção para idioma, foram utilizados os artigos em português e inglês, que abordassem a importância da relação LA:LNA na alimentação das aves poedeiras para melhorar o desempenho de incubação e o enriquecimento dos ovos, além da utilização de livros para o 
embasamento dos conceitos. No processo de pré-seleção dos artigos foram coletados 92, entretanto alguns deles apresentavam objetivos diferentes, então como critério de exclusão, foram retirados 14 destes artigos. Portanto foram utilizados para a realização desta revisão 76 artigos e 2 livros cujas informações eram pertinentes sobre o assunto abordado neste material.

\section{Revisão Bibliográfica}

\subsection{Lipídios}

Os lipídios podem ser definidos como um grupo heterogêneo com compostos quimicamente diferentes entre si, insolúveis em água e solúveis em solventes orgânicos. Sendo divididos em: triacilgliceróis, fosfolipídios, colesterol, ácidos graxos entre outros. E classificados de acordo com a sua função, como: lipídios de reserva (triacilgliceróis), lipídios estruturais de membrana (fosfolipídios), sinalizadores, cofatores e pigmentos (Lehninger et al., 2014).

Dentre os lipídios, os triglicerídeos são os encontrados em maior abundância na natureza, sendo esse a principal fonte de energia, componente das membranas celulares e fonte de ácidos graxos, e é composto por dois ácidos graxos ligados a uma molécula de glicerol, por meio de ligações ésteres e um grupo fosfato (Lehninger et al., 2014).

A digestão e absorção dos lipídios ocorre através da hidrolise desses compostos, cujas cadeias liberam glicerol, ácidos graxos, monoacilgliceróis, fosfogliceróis, esteróis e isoprenoides. No processo digestivo dos lipídios, eles são emulsificados pelos sais biliares em fosfolipídios para que a molécula fique menor e tenha maior superfície de contato, facilitando a ação das lipases que farão a hidrólise das cadeias, originando ácidos graxos e glicerol. Os ácidos graxos em associação com os monoglicerídeos e sais biliares dão origem as micelas que ao entrarem em contato com a mucosa intestinal liberam os monoglicerideos dentro dos enterócitos. Depois desse processo os ácidos graxos são reesterificados formando triacilgiceróis, que se combinam a uma proteína transportadora formando o quilomícron, que cai no sistema linfático e é transportado para o fígado e outros tecidos do corpo (Phetteplace \& Watkins, 1990; Nimpf \& Schneider, 1991).

A absorção dos ácidos graxos nas aves ocorre após a hidrolise dos triglicerídeos que libera os ácidos graxos. Estes são absorvidos pelo sangue e vão para o sistema porta-hepático. Os triglicerídeos e colesterol em excesso nos hepatócitos são utilizados para sintetizar as lipoproteínas de baixa densidade, e a medida que essas lipoproteínas circulam pelos capilares extrahepáticos, os triglicerídeos vão sendo hidrolisados pelas lipoproteínas dando origem a lipoproteína de densidade intermediária, IDL, que também será transformada em lipoproteínas de baixa densidade (Lehninger et al., 2014).

Dessa forma, os lipídios são amplamente utilizados na alimentação animal, esse nutriente fornece grandes quantidades de energia prontamente disponível. No organismo animal, possuem função de regulação do metabolismo, constituindo parte da estrutura das prostaglandinas e hormônios esteroides, produção e armazenamento de energia, sendo a principal fonte de ácidos graxos essenciais (Marke et al., 2016).

Os ácidos graxos são encontrados nas gorduras de origem animal e vegetal, sendo divididos em ácidos graxos saturados, monoinsaturados e poli-insaturados. Recebendo essa classificação levando em conta os números de ligações. Os ácidos graxos saturados (AGS) possuem apenas ligações simples de carbono, já os insaturados têm uma ou mais duplas ligações de carbono. Os ácidos graxos insaturados (AGI) podem ser divididos em monoinsaturados (MUFAS), que possui apenas uma dupla ligação na cadeia de carbono e poli-insaturados (PUFAS) que possuem mais de uma dupla ligação na cadeia de carbono (Lehninger et al., 2014).

\section{2 Ácidos graxos poli-insaturados: ômega 3 e ômega 6}

As PUFAS abrangem as famílias de ácidos graxos n-3 e n-6, que são considerados essenciais pois compõem uma classe de moléculas que não podem ser formadas pelo organismo. Porém, são indispensáveis para o seu funcionamento. O ômega 3 (n-3) e o ômega 6 (n-6) apresentam a sua primeira dupla ligação no terceiro e sexto átomo de carbono a partir do 
carbono metílico terminal, respectivamente, estando os nomes dos ácidos graxos relacionados com o local das duplas ligações (Cedro et al., 2010).

Os principais representantes do n-3 são o ácido $\alpha$-linolênico ou ALA (18:3n-3), o ácido eicosapentaenoico ou EPA (20:5n-3) e o ácido docosaexaenoico ou DHA (22:6n-3). Para a família do n-6 os principais são o ácido linoleico ou LA (18:2n-6) e o ácido araquidônico ou AA (20:4n-6) (Perini et al., 2010).

O n-3 é precursor do DHA e do EPA, enquanto que o n-6 origina o AA, esses ácidos são sintetizados no retículo endoplasmático liso, principalmente no fígado, por sucessivas reações de dessaturações (oxidação com formação de duplas ligações) e alongamentos (aumento da cadeia carbônica com adição de átomos de carbono). As reações de dessaturações são catalisadas principalmente por duas enzimas: a delta $6(\Delta 6)$ e delta $5(\Delta 5)$ dessaturase. A $\Delta 6$ dessaturase é a enzima que regula a biossíntese das PUFAS. Sua atividade depende da competição entre substratos e de um feedback para regulação, que será mediada por ambos os produtos intermediários e finais (Lehninger et al., 2014).

A metabolização do $\alpha$ ácido linolênico ocorre pela sua dessaturação (inserção de ligações duplas na cadeia acil), pelas enzimas $\Delta 5$ e $\Delta 6$, e pela sua elongação através da enzima elongase. O primeiro passo é a conversão do $\alpha$ - ácido linolênico (18:3n-3) em ácido estearidónico (18:4n-3) pela ação da $\Delta 6$ dessaturase, sendo em seguida elongado a ácido eicosatetraenoico (20:4n-3), que vai ser convertido em EPA, via $\Delta 5$ dessaturase (Figura 2). O EPA pode seguir duas vias, uma é ser metabolizado a DHA, ou então dar origem a eicosanoides através de ciclooxigenases (COXs) ou lipooxigenases (LOXs) (Sprecher, 2000).

A segunda via é a de transformação do EPA em DHA que ocorre através a adição de dois carbonos no EPA, via elongase, formando o ácido docosapentaenoico (22:5n-3). Esse sofre ações da elongase quando ocorre a adição de mais dois carbonos formando o ácido tetracosapentaenoico (24:5n-3). Após essas duas elongações ocorre a dessaturação catalisada pela $\Delta 6$ dessaturase, cujo produto formado é o ácido tetracosahexaenoico (24:6n-3), em seguida ocorre a remoção de dois carbonos por um processo de $\beta$-oxidação, originando o ácido docosahexaenoico (22:6n-3) (Sprecher, 2000) (Figura 1).

Figura 1. Metabolismo do $\alpha$ - ácido linolênico. Fonte: Adaptado de Briz,1997.
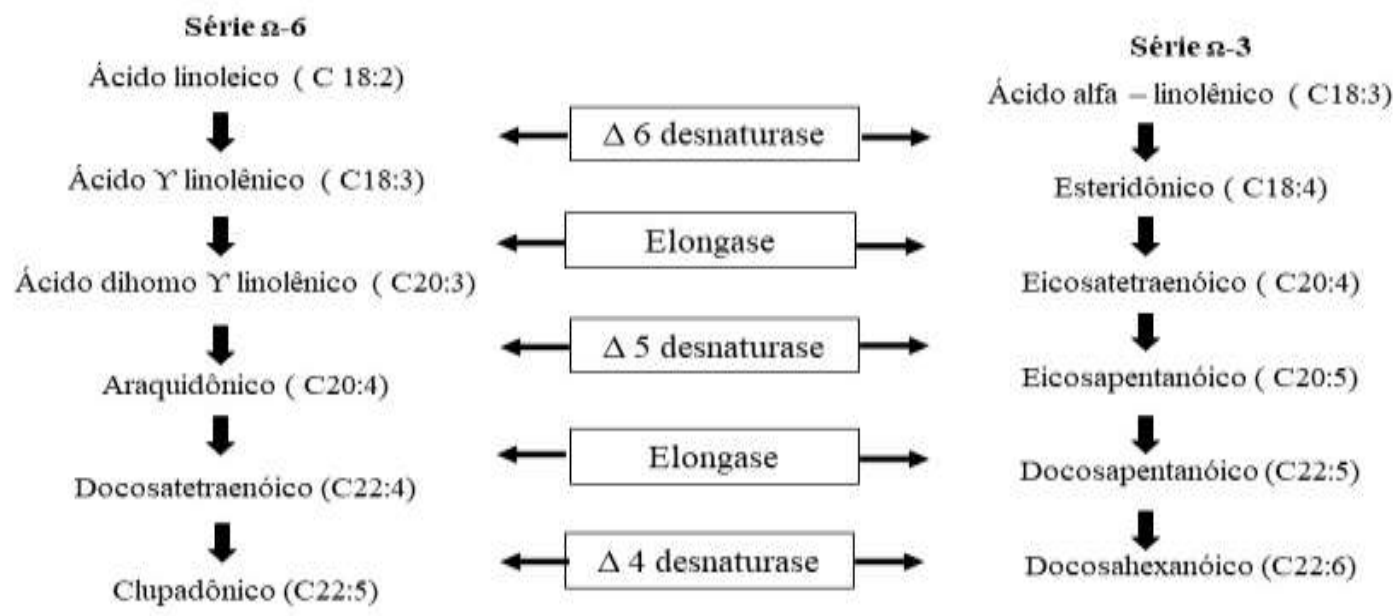

Fonte: Autores.

A metabolização do ácido linoleico (18:2 n-6) utiliza as mesmas enzimas envolvidas no $\alpha$ - ácido linolênico. Ocorre a conversão do ácido linoleico em ácido $\Upsilon$ - linolênico (18:3n-6) pela ação da $\Delta 6$ dessaturase, em seguindo sofre a ação da elongase que vai a dihomo $\Upsilon$-linolênico (20:3n-6), que é convertido em AA, via $\Delta 5$ dessaturase. O AA ainda pode sofrer mais duas ações da elongase e se tornar outros ácidos graxos (ácido docosatetraenoico 22:4n-6 e ácido tetracosatetraenoico 24:4 n- 
6), os produtos formados sofrem a ação da $\Delta 6$ originando o ácido tetracosapentaenoico (24:5), que ao ocorrer a $\beta$ oxidação peroxissomal forma o ácido docosapentaenoico (22:5) (Sprecher, 2000) (Figura 1).

Dentre as funções desses ácidos, o DHA ajuda no funcionamento e desenvolvimento da retina e cérebro, sendo predominante na maioria das membranas celulares. A deficiência de n-3 diminuiu a concentração de DHA nesses tecidos, tendo influências sobre a funções dos mesmos (Jacobsen et al., 2013).

A produção de prostaglandina está associada ao EPA e o AA. A prostaglandina tem função de regular e proteger o organismo de efeitos, como inflamação, agregação plaquetária e diminuição das respostas imunes (Perini et al., 2010). O EPA e o AA produzem os eicosanoides que são mediadores inflamatórios, e o AA é o principal substrato para a síntese dos eicosanoides. O AA também possui funções sobre o crescimento fetal, no controle da pressão sanguínea e no controle da agregação plaquetária (Di Natale et al., 2011).

\subsection{Relação de n-6: n-3}

No metabolismo dos ácidos linoleico e linolênico (n-6:n-3), ambos vão utilizar as mesmas enzimas elongase e dessaturase, ocorrendo uma competição pela utilização dessas enzimas no organismo. A taxa de conversão do $\alpha$ linolênico é muito baixa em humanos e nas aves e ocorre a diminuição à medida que a quantidade de ácido linoleico aumenta. $\mathrm{O}$ ácido graxo alfa linolênico possui baixo efeito biológico, e necessita ser convertido a EPA e DHA, pois são incorporados mais facilmente nos lipídios das membranas celulares (Cherian, 2008).

Apesar de haver competição entre as enzimas de dessaturação e alongamento, é possível observar que os ácidos graxos da família n-3 possuem maior afinidade, podendo assim ser fornecido em menor quantidade que os da família n-6 para produzir a mesma quantidade de produto (Perini et al., 2010). Essa relação entre as famílias de ômega 3 e 6 podem ser manipuladas pela alimentação animal, levando em consideração os ingredientes contidos na ração. Um desbalanço entre esses ácidos pode diminuir a atuação dos mesmos no organismo (Dalla Costa et al., 2017). Nas rações comerciais para aves não são encontradas boas relações, pois em sua composição aproximadamente 50\% é composto de n-6, enquanto 3-3,5 \% é de n-3, esse desbalanço ocorre por causa do maior teor de n-6 encontrados no milho e óleo de soja (Rostagno, 2017).

Além do desbalanço entre os ácidos, a ingestão insuficiente de ômega 3 desencadeia o processo de substituição pelos ácidos palmitoleico (C16:1) e oleico (C18:1), que são dessaturados e alongados, formando ácidos eicosatrienoicos. Com esse desequilíbrio no organismo é observado prejuízo em ovos comerciais incubados que apresentam baixa concentração de n-3, refletindo muitas vezes na baixa fertilidade de algumas aves (Cherian, 2008).

Esta relação é algo de extrema importância a ser considerado na alimentação animal, visto que a gordura enriquecida com ácidos graxos ômega $3 \mathrm{em}$ maior quantidade que o ômega 6 representa um alimento mais saudável pela funcionalidade do ácido linolênico no organismo (Vaz et al., 2014; Stefanello et al., 2019). Entretanto, o aumento do nível total de PUFAS representa risco a qualidade de produtos processados por causa da maior fluidez da gordura, que permite maior suscetibilidade a oxidação da gordura, dessa forma, é importante que o enriquecimento do ômega 3 não seja acompanhada do aumento de ômega 6 (Dalle Zotte \& Szendro, 2011).

O balanço adequado na proporção n-6:n-3 na dieta é essencial para o metabolismo do organismo, visto que os ácidos n-6 e n-3 são metabolicamente diferentes, apresentando funções fisiológicas opostas (pró e anti-inflamatória, respectivamente), por esses fatores o equilíbrio nutricional é importante para se obter a homeostasia e o desenvolvimento normal do organismo. Algumas recomendações para humanos dessa relação são ácidos graxos ômega 6/ômega 3, de 5:1 até 10:1. (Santos et al., 2013).

Segundo Araújo et al. (2019), o óleo de soja possui a cada 100 gramas um percentual 55,02\% de n-6 em sua composição, e 5,2\% de n-3, obtendo a relação de 10,58 de n-6:n-3. Já no óleo de linhaça é composto de 14,98\% n-6, enquanto 
50,13\% composto de n-3 obtendo a relação n-6:n-3 de 0,30. Sendo assim, dietas com altos teores de óleo de soja apresentam alta relação de n-6:n-3 na dieta.

Antes da industrialização na alimentação humana a relação de n-6:n-3 seriam próximo de 1:1 a 2:1, pelo alto consumo de vegetais e alimentos de origem marinha, com a industrialização houve queda no consumo desses alimentos e aumento no consumo de óleo refinados de espécies oleaginosas com altos teores de n-6, resultando em aumento na relação n-6:n-3 para 10:1 a 20:1 e, por isso, a busca por alimentos para diminuir essa relação vem crescendo nos últimos anos e como peixe é uma fonte cara de n-3 o enriquecimento de produtos avícolas é uma alternativa barata para diminuir essa relação (Simopoulos, 2004).

\subsection{Fontes de ácidos graxos}

As principais fontes de ácido linoleico são as sementes de plantas oleaginosas como soja, milho, girassol e as castanhas, oleaginosas essas que são utilizadas na produção de óleos. No entanto, o ácido $\alpha$-linolênico é encontrado principalmente em peixes de águas frias e profundas (óleos de peixes) e em algumas oleaginosas como o óleo de linhaça (Saini e Keum, 2018).

O óleo de soja é caracterizado por apresentar em sua composição alta concentração de PUFAS sendo 38,72 \% de ácido linoleico (C18:2) e 11,47 \% de ácido linolênico (C18:3) (Missão, 2006). Rostagno (2017), descreve que a composição do óleo de soja possui $9333 \mathrm{Mcal} / \mathrm{kg}$ de energia metabolizável, 52,6 \% de ácido linoleico (C18:2) e 6,94 \% de ácido linolênico (C18:3).

O óleo de soja é muito utilizado na nutrição animal por seu valor energético. Pesquisas comprovam que esse óleo está associado ao aumento do peso do ovo, por causa dos níveis elevados de ácido linoleico (Jiang et al., 2014). Esse ácido promove o aumento das concentrações de estrógeno e, assim estimula a síntese proteica no oviduto, ocasionando maior deposição de proteína no albúmen, resultando em um ovo mais pesado.

Güçlü et al. (2008), ao utilizarem codornas japonesas com 12 semanas de idade e adicionar na dieta a inclusão de 4\% de diferentes fontes de lipídios, sendo seis de óleo vegetal (girassol, gergelim, algodão, oliva, avelã, milho e soja) e uma fonte de origem animal (peixe), observaram aumento do teor de omega-3 na gema do ovo das aves que foram suplementadas com o óleo de peixe e óleo de soja, outro efeito observado do óleo de soja foi o aumento na concentração de lipídeo sérico dos animais.

O óleo de linhaça apresenta em sua composição alto teor de ácidos linolênico e apresenta relação de 1:4 de n6/n3, sendo considerada baixa, ideal para balancear a razão da dieta total. A utilização do óleo de linhaça na dieta de poedeiras promove enriquecimento nos ovos, pois aumenta a concentração de ácido linolênico, com a incorporação de pequenas quantidades de EPA e DHA e reduz a relação n6:n3, que irá beneficiar o animal e o indivíduo consumidor do ovo (Oliveira et al., 2010; Santillo et al., 2016; Santos et al., 2016).

Em virtude da alta concentração de ácido alfa linolênico, o óleo de linhaça possui alto valor, por causa de sua composição há crescente interesse no uso de sementes de linhaça para aves com o intuito de produzir ovos enriquecidos com ácido graxo da família ômega 3 , além dos benefícios que essa fonte lipídica proporciona para o organismo das aves. Apesar do seu alto custo, tem sido utilizado em substituição aos óleos marinhos que possuem maior valor de mercado (Leeson e Summers, 2001). 


\subsection{Lipídios na dieta de aves}

\subsubsection{Formação e deposição de lipídios na gema do ovo}

Os lipídios da gema do ovo são sintetizados no fígado e transportados pela corrente sanguínea na forma de lipoproteína de densidade muito baixa (VLDL), para os folículos em desenvolvimento, sendo depositado via endocitose mediada por receptor (Neves \& Henry, 2012). Na gema os principais lipídios são as lipoproteínas que representam, aproximadamente $95 \%$ dos lipídios da gema, quando presente no oocisto em desenvolvimento que se complexam com fosfolipídios e colesterol. As aves utilizam um VLDL especial, denominado gema-marcado (VLDLy), que tem propriedades estruturais e bioquímicas únicas para transportar triglicerídeos e fosfolipídios do fígado para o ovário (Jucobsen et al.,2013)

Os triglicerídeos VLDLy possuem pequeno tamanho e são capazes de atravessar a lâmina basal granulosa do folículo ovariano e se unir ao receptor de apolipoproteína-B na oolema, sendo absorvida intacta para formar a gema (Dalla Costa et al., 2017). As estruturas presentes nos folículos e tamanho das VLDLy possibilitam a alteração da gordura dietética pelo fígado antes desses lipídios serem incorporados na gema dos ovos. Porém, esta modificação hepática não ocorre totalmente, possibilitando assim que a composição de lipídios da dieta reflita na composição de lipídios da gema, principalmente as concentrações de ácidos graxos (Dalla Costa et al., 2017).

A combinação entre as estruturas do folículo ovariano e a VLDLy que ocorre no fígado é o que possibilita manipular através da dieta a modificação da gordura que será depositada na gema no ovo. Assim, a composição lipídica da gema e da dieta são semelhantes, a dieta oferecida às aves e os níveis plasmáticos de lipoproteínas plasmáticas possuem relação direta com a manipulação do perfil de ácidos graxos da gema dos ovos (Dalla Costa et al., 2017).

Os lipídios que circulam no plasma são provenientes do aporte intestinal, da síntese hepática e da mobilização de gordura estocada no organismo (Freitas et al., 2012). A concentração no sangue dos diferentes lipídios sofre interferência de diversos fatores como: espécie, idade, sexo, estágio reprodutivo, presença de doenças e principalmente da quantidade de ácidos graxos presente na dieta (Santos et al., 2013). Para promover uma nutrição adequada para o embrião, a ave em idade reprodutiva aumenta a produção de colesterol hepático

\subsubsection{Composição do ovo de codorna}

O ovo de codorna é composto por $8 \%$ de casca, $32 \%$, gema e $60 \%$ de albúmen e os principais componentes são água $75 \%$, lipídios $12 \%$, proteína $12 \%$ e em menores concentrações carboidratos, minerais e vitaminas (Genchev, 2012). A gema e albúmen apresentam composições diferentes, enquanto as proteínas são distribuídas nos dois componentes, os lipídios estão presentes quase exclusivamente na gema (Oliveira et al., 2010). O albúmen possui em sua composição, aproximadamente, 88\% de água e $12 \%$ de sólidos totais, dos quais $11 \%$ são proteína e o restante são minerais e carboidratos. Já na composição da gema essas proporções mudam sendo 50\% de água, 16\% de proteína e 34\% de lipídios (colesterol, triglicerídeos e fosfolipídios (Medeiros e Alves, 2014). Apesar das diferenças entre os compartimentos do ovo a composição pode ser modificada de acordo com a alimentação da ave

O ovo e a carne de codorna possuem valores nutricionais semelhantes ao da galinha e frango, respectivamente. Possuindo aproximadamente $12 \%$ a mais de proteína no ovo comparado com o de galinha e a carne com $1 \%$ a mais de proteína. Apresenta também um teor mais baixo de colesterol no ovo que o de galinha. O peso médio do ovo de codorna é próximo de 10 a 11 gramas, e equivale a $1 / 5$ do peso do ovo de galinha, na sua composição possui carboidratos 4,01 g, cinzas 1,06 g, proteína bruta 12,7 g, extrato etéreo 9,89 g, umidade 72,25 g e o seu teor energético equivale a 156,50 kcal. Os valores de proteína, carboidrato, gordura e energia foram maiores na gema do ovo de codorna que o comparados com ovos inteiros de galinhas (ovos brancos) (Tunsaringkarn et al., 2013) 


\subsection{3 Ácidos graxos no ovo}

A modificação do perfil lipídico da ração das poedeiras altera o perfil lipídico do ovo, principalmente da gema, já que os lipídios presentes nas rações vão ser digeridos e absorvidos e enviados para a gema, tendo assim a mesma composição (AlDaraji et al., 2010). Essas modificações dos lipídios, estão mais focadas na composição de ácidos graxos da gema, com isso, o ovo vai se tornar uma opção para suplementação de AGIs (Al-Daraji et al., 2010).

Os lipídios, os componentes mais abundantes da gema, e representam aproximadamente $60 \%$ do peso total da gema com base na matéria seca os constituintes as lipoproteínas de baixa LDLs (Low Density Lipoprotein) e alta densidade HDLs (High Density Lipoprotein), triglicerídeos, fosfolipídios, colesterol livre e outros de menor quantidade (Jacobsen et al., 2013). Os triglicerídeos compõem a cerca de $65-68 \%$ e os fosfolipídios 29-32\% dos lipídios da gema. Os ácidos graxos são os principais componentes dos triglicerídeos e fosfolipídios, correspondendo aproximadamente $4 \mathrm{~g}$ do peso do ovo de galinhas (Jacobsen et al., 2013).

O nível de inclusão e a qualidade da fonte lipídica são os principais fatores que podem afetar o valor nutricional dos ovos. Galinhas alimentadas apenas com óleo de soja produzem ovos com maiores quantidades de ácidos graxos n- 6 . Ao mesmo tempo que galinhas alimentadas com apenas óleo de linhaça apresentam ovos com altos teores de ácidos graxos n-3 (Oliveira et al., 2011). Segundo Tunsaringkarn et al. (2013) os ovos de codornas possuem alta concentração de lipídios, tendo 1,8 vezes mais AGI comparados aos AGS. Com relação a proporção encontrada em 100g da gema, 7,41 g foi de AGS 13,32 g AGI dividido em MUFAS 9,64 g e PUFAS 3,68 g. Dentre os PUFAS, o perfil de ácido graxo essenciais na gema do ovo foi 2,58 g ácido linoleico, 0,50 g ácido DHA e 0,44 g de AA.

O aumento de ômega 3 na dieta não indica que haverá aumento dos valores de EPA e DHA na mesma proporção, o que aumenta é a concentração de $\alpha$-linolênico que será utilizado para sintetizar o EPA e DHA. A manipulação desses ácidos na alimentação das aves é a principal ferramenta para melhorar o perfil de ácidos graxos na gema do ovo, garantindo a transferência de n-3 e n-6 da gema para os tecidos embrionários e para a progênie, além de melhorar as variáveis de incubação (Khatibjoo et al., 2018). Dentre as formas de inclusão do ômega 3 na dieta, observa-se a utilização de algas marinhas.

Outro fator a ser considerado é a taxa de deposição de ácidos graxos varia com a idade e com a linhagem das galinhas. Ovos de galinhas alimentadas com rações com relações balanceadas de PUFA, com relação de n-6:n-3 de 1:1 fornecem na composição dos ovos mais de $600 \mathrm{mg}$ de n-3 (Ahmad et al., 2012).

Na Tabela 1 são apresentados os dados da composição de ácido graxos nos ovos de codornas e galinha, podendo ser observado que os ovos de codorna mesmo sem ser enriquecido apresentam valores maiores de ácidos graxos quando comparados com o ovo de galinha, apresentando alta concentração de PUFAS $(2,70)$, tendo maior concentração de linolênico 2,20 nos ovos de codorna. Outros trabalhos corroboram com essa afirmação mostrando que os ovos de codornas possuem maior conteúdo de DHA (1,72\%) quando comparados com os ovos de galinhas $(0,56 \%)$ e em relação de n-6:n-3 as codornas apresentam menor relação 5:6 e as galinhas 14:2 (Lima et al., 2011). Genchev (2012) ao avaliar o perfil lipídico da gema de codornas japonesas observou que o teor de PUFA é a cerca de 2,5 vezes maior na fração fosfolipídica que na fração de triglicerídeos, sendo 44,3\% de AGS e 55,7\% de AGI. Na fração fosfolipídica foi encontrado de AGS, 29,77\% para ácido palmítico, 14,53\% para esteárico, já de MUFAS 3,79\% para palmitoleico, e 28,9\% para oleico, enquanto que para os PUFAS foram encontrados 15,59\% de ácido linoleico e araquidônico com 7,42\%. 
Tabela 1. Composição dos ácidos graxos por 100 gramas de parte comestível de ovo inteiro.

\begin{tabular}{|c|c|c|}
\hline Ácidos Graxos & Ovo de Codorna & Ovo de Galinha \\
\hline ÁGS (g) & 8,90 & 2,60 \\
\hline ÁGI (g) & 12,10 & 3,60 \\
\hline PUFAS (g) & 2,70 & 1,20 \\
\hline Mirístico (14:0) (g) & 0,13 & 0,02 \\
\hline Palmítico (16:0) (g) & 6,39 & 1,87 \\
\hline Esteárico (18:0) (g) & 2,31 & 0,69 \\
\hline Araquídico (20:0) (g) & 0,01 & - \\
\hline Behênico (22:0) (g) & 0,03 & 0,01 \\
\hline Lignocérico (24:0) (g) & - & 0,01 \\
\hline Miristoleico (14:1) (g) & 0,03 & - \\
\hline Palmitoleico (16:1) (g) & 1,07 & 0,23 \\
\hline Oleico $(18: 1)(\mathrm{g})$ & 11,01 & 3,33 \\
\hline Gadoleico $(20: 1)(\mathrm{g})$ & 0,03 & 0,01 \\
\hline Linoleico $(18: 2 \mathrm{n}-6)(\mathrm{g})$ & 2,20 & 0,88 \\
\hline Alfa-Linolênico (18:3 n-3) (g) & 0,10 & 0,02 \\
\hline Araquidônico (20:4) (g) & 0,44 & 0,14 \\
\hline Clupadônico (22:5) (g) & - & 0,05 \\
\hline DHA $(22: 6)(\mathrm{g})$ & - & 0,04 \\
\hline Elaídico (18:1t) (g) & 0,04 & - \\
\hline Trans-octadecadienoico (18:2t) (g) & 0,07 & - \\
\hline
\end{tabular}

Fonte: Adaptado de Lima et al. (2011).

\subsection{4 $O$ enriquecimento de ovos com ômegas 3 e 6 através da dieta das aves}

A manipulação da dieta das aves é uma das maneiras mais eficientes para enriquecer os ovos com ácidos graxos das séries ômega 3 e 6, sabe-se que com enriquecimento é possível alterar a composição e a proporção dos ácidos graxos da gema, porém, não é possível modificar o percentual lipídico dos ovos (Dalla Costa et al., 2017). Para o enriquecimento dos ovos com ômega 3 a fonte de origem vegetal mais utilizada é a semente de linhaça. Por possuir boa estabilidade e alto conteúdo de ômega 3, dentre outros valores nutritivos, como energia e proteína (Jacobsen et al., 2013).

Quando utilizados os óleos separados, os ovos são enriquecidos apenas com o ácido graxo predominante naquele óleo, como observado por Oliveira et al. (2010) que ao fornecerem dieta rica em óleo de soja para galinhas, elas produziram ovos com maiores quantidades de PUFAS n-6, enquanto galinhas alimentadas com óleo de linhaça apresentaram ovos com maiores quantidades de PUFAS n-3. Esses resultados comprovam que a qualidade nutricional dos ovos pode ser modificada 
dependendo da quantidade e fonte lipídica adicionada nas dietas, sendo assim fonte viável para produzir alimentos mais saudáveis, com maior valor agregado e ovos melhores para nutrição embrionária (Araújo et al., 2019).

A relação n-6:n-3 é outra característica importante na determinação de boa relação do ovo na alimentação humana, considerando os efeitos benéficos dos PUFAS. Porém, essa relação também é importante para o desenvolvimento embrionário, já que esses ácidos graxos também são utilizados na nutrição do embrião. Assim, a utilização do óleo de linhaça é uma opção de enriquecimento dos ovos em n-3, diminuindo a relação e nutrindo melhor o embrião (Petrović et al., 2012).

Experimentos que fornecerem fontes de ômega 3 oriundas de algas marinhas (1,5\%) e óleo de peixe $(1,8 \%)$ para aves poedeiras demonstram que a inclusão de ambos os tratamentos na ração conteve maiores teores de MUFAS e PUFAS da série n-3 que o tratamento controle, enquanto que este último apresentou altos teores de PUFAS da série n-6 e AGS, apesar da variação todos os tratamentos apresentaram características externa e interna desejáveis (Cedro et al., 2011). Em outro experimento, Bruneel et al. (2013), suplementaram diferentes níveis crescentes de microalgas ( $0 ; 5$ e 10\%) para poedeiras e analisaram o teor lipídico dos ovos em quatro momentos, sendo 0, 14, 28 e 42 dias. Os resultados demonstraram que houve um enriquecimento de ômega 3 nos ovos das aves suplementadas nos dias 14 e 28. Aos 42 dias não houve diferença estatística entre os PUFAS, sendo todos estatisticamente iguais ao grupo controle.

Lemahieu et al. (2015), ao avaliarem o perfil lipídico de ovos de poedeiras sob a inclusão de diferentes fontes de PUFAS da série n-3 (linhaça, Isochrysis galbana, óleo de peixe e DHA ouro®) observaram que o menor nível de enriquecimento no ovo foi realizado pela linhaça com $6 \%$, aproximadamente, enquanto que as outras fontes foram estatisticamente superiores, sendo de 30\% Isochysis galbanae 45\% para o DHA ouroß e de 55\% para o óleo de peixe.

\subsection{Efeito dos ácidos graxos na embriogênese e progênie}

Os lipídios da gema desempenham papel crucial como fonte de energia e nutrientes essenciais no desenvolvimento embrionário das aves. Mudanças na composição dos ácidos graxos na gema podem ter efeitos benéficos ou colaterais para a sobrevivência do embrião. Um ovo médio tem aproximadamente 5,5 - $6 \mathrm{~g}$ de lipídios totais e está presente como lipoproteínas na gema. Os lipídios totais possuem a cerca de $65 \%$ de triacilglicerol e $28 \%$ de fosfolipídios (Cherian, 2007).

Durante o período de incubação mais de $88 \%$ de triacilgliceróis e $95 \%$ de fosfolipídios são absorvidos pelo embrião em crescimento. A rápida aceitação dos diferentes componentes lipídicos pelo embrião começa a partir da segunda semana de incubação e continua até que a gema residual seja completamente absorvida (Speake et al., 1998). Entre os diferentes lipídios tomadas pelo embrião de pintos, o triacilglicerol serve como fonte de energia, enquanto fosfolipídios servem como precursores estruturais essenciais para bicamadas de lipídios de membrana (Speake et al., 1998).

Além da utilização do lipídio para a beta oxidação de ácidos graxos, estes também são utilizados por tecidos embrionários específicos, enquanto as outras frações lipídicas são utilizadas para diversas funções como a biogênese da membrana, sinal de transdução e a síntese de hormônios esteroides que envolvem uma rede complexa de composição, mecanismos de transporte, captação específica de tecido e metabolismo. Esses processos têm impacto na composição lipídica dos tecidos nos diferentes estágios específicos. Com isso existe certos tipos de tecidos que possuem um perfil lipídico quando embrião e outro quando pinto (Nobel \& Cocchi,1990)

No início da incubação nem todos os ácidos graxos são detectados, isso ocorre principalmente com o DHA que é dificilmente detectável nos triglicerídeos da gema inicial, mas ao analisar o triacilglicerol em pintos de galinhas no $12^{\circ}$ dia de incubação os ácidos graxos constituíam $20 \%$ do peso total. Esse ácido é encontrado principalmente no cérebro e retina. Além disso, há considerável evidências de que o DHA desempenha papel importante no desenvolvimento funcional do tecido do sistema neural e que deficiências no fornecimento deste ácido graxo, danificam o cérebro e retina durante a vida embrionária e isto pode resultar em uma série de deficiências comportamentais e visuais (Neuringer at al., 1998). 
No processo de incubação ocorrem diversas mudanças na composição dos ácidos graxos da gema, porque mais de 90 $\%$ da energia que deriva do embrião é originária da oxidação dos lipídios da gema. Outra característica é a intensidade de transferência de lipídios da gema do embrião durante a segunda metade do período de incubação. Como consequência, variedades de enzimas estão envolvidas no metabolismo dos lipídios que possuem atividades muito elevadas nos tecidos do embrião nesta fase (Cherian \& Sim, 1992). Por isso, é tão importante a composição de ácidos graxos da gema e as transformações que acontecem na sua composição para diversos momentos do desenvolvimento dos pintos.

Buyse et al. (2014) ao utilizarem DHA e EPA na dieta com relação de 1:1, 1:2 e 2:1 (sendo a relação de n-6: n-3 na proporção de 11 a 5,4), observaram que a gema, tecidos embrionários e descendentes apresentavam a mesma proporção presente na dieta. Isso ocorre porque as suplementações lipídicas maternas são adicionadas na gema na mesma quantidade, principalmente os ácidos graxos, esses ovos enriquecidos ao serem incubados transferiam os ácidos graxos para o embrião através da gema residual, resultando em altas concentração de EPA e DHA no fígado de pintinhos após a eclosão.

Os AA e o DHA são importantes durante o processo de incubação, mas também são importantes no período pósincubação. Vai ajudar na rápida proliferação de células, e um intenso acúmulo de tecido, após a incubação, além de atuar na maturação dos órgãos linfoides (Cherian e Sim, 1992). A maior quantidade de lipídio utilizado para o desenvolvimento do embrião ocorre durante a última semana de incubação, sendo que grande proporção é utilizada pelo pinto até o quinto dia após o nascimento. Os pintos obtêm esses lipídios através da gema pela via lipoproteica (Latour et al., 1995).

A manipulação da relação de n-3 para n-6 em dietas de matrizes melhora o perfil de ácido graxo na gema, melhorando a incorporação de n-3 e n-6 nos tecidos embrionários. O n-3 presente na gema tem papel importante na modulação do metabolismo de progênie de lipídios e eicosanoides, são preferencialmente retirados dos lipídios do saco vitelino e são incorporados em fosfolipídios da membrana celular do embrião em desenvolvimento durante embriogênese e crescimento pósnascimento (Delezei et al., 2014; Koppenol et al., 2015).

Ao avaliar a transferência do n-3 em ovos enriquecidos durante a incubação, foi observado aumento significativos na incorporação de EPA e DHA no tecido hepático e cerebral dos pintinhos. Isso sugere que o embrião em desenvolvimento sintetiza esses ácidos a partir do precursor $\alpha$-linolênico presente na gema do ovo, os PUFA n-3 de cadeia longa apresentam funções no sistema imunológico, desenvolvimento do sistema nervoso central e metabolismo lipídico (Cherian \& Sim, 1993). Pintos nascidos de fêmea cuja dieta rica em n-3, obtêm alteração na dessaturase hepática da atividade enzimática, afetando o metabolismo dos ácidos graxos de cadeia longa (Cherian e Sim, 2001). Além disso, aumentam a retenção de n-3 em diversos tecidos da progênie e com isso apresentam mudanças nas respostas imunes e na síntese de eicosanoides derivados do n-3, esses resultados mostram que o omega-3 da gema tem importante papel na modulação dos lipídios e metabolismo do eicosanoides na progênie (Cherian, 2008).

Os ácidos graxos que são incorporados na gema são essenciais para o início do desenvolvimento da progênie. Na incubação de ovos de matrizes pesadas, cuja duração leva 21 dias, o terço final é o período mais intenso do metabolismo lipídico e rápido crescimento embrionário (Gonçalves et al., 2013). Estima-se que mais de $90 \%$ da necessidade total de energia para o desenvolvimento embrionário é derivada da oxidação dos ácidos graxos dos lipídios da gema. E, mais de $80 \%$ dos lipídios da gema são absorvidos pelo embrião em desenvolvimento, servindo como fonte de energia e ácido graxo essencial (Scottá et al., 2014). Além dessas funções, os lipídios também contribuem para fosfolipídios estruturais embrionários através do fornecimento de PUFAS de cadeia longa (> 20C), como AA, EPA e DHA. Após o nascimento do pintinho ocorre a absorção do complexo residual da gema na cavidade abdominal e o metabolismo do lipídio da gema continuam e são suficientes para a manutenção do pintinho por aproximadamente dez dias após o nascimento (Nobel \& Cocchi, 1990).

Um dos motivos que pode influenciar na baixa eclodibilidade é a redução na transferência de lípidios da gema para o embrião, essa transferência incompleta impede o acesso aos nutrientes pelo embrião (Koppenol et al., 2014). Saber et al. 
(2020), demonstraram que a deficiência de ácidos graxos essenciais na alimentação de galinhas resultou em uma progênie que eclodiu tardiamente do que a progênie de galinhas cuja dieta não era deficiente em ácidos graxos essenciais.

Ao incluir 3\% de óleo de peixe ou linhaça em compração com o óleo de girassol, para reprodutoras de codornas japonesas foi observado um aumento na concentração de n-3. Esse aumento teve efeito sobre o tamanho do ovo, aumento da eclodibilidade e fertilidade e a diminuição da mortalidade embrionária precoce (Al Daraji et al., 2010).

\subsection{Efeitos dos ácidos graxos na fertilidade}

Um dos fatores que afetam a interação espermatozoide: óvulo é a capacidade do espermatozoide conseguir entrar e ser armazenado nos túbulos de armazenamento na mucosa da vagina das fêmeas (Bromfield et al., 2015). Alguns problemas que podem afetar esta interação são espermatozoides sem cauda, desformes ou mesmo com a camada lipídica alterada diminuindo a capacidade de sobreviver a seleção e o armazenamento, reduzindo a fertilidade (El-Desoky et al., 2017).

Com isso, as dietas modificam a capacidade de fertilização dos espermatozoides, visto que os lipídios afetam a estrutura da membrana e a peroxidação. Isso ocorre pelas alterações de fosfolipídios específicos, ácidos graxos ou desbalanço da n-6:n3 (Blesbois et al., 1997). Ao alimentar reprodutores de frangos com óleo de peixe foi observado que os PUFAS n-3 foram transferidos com sucesso para os espermatozoides (Cerolini et al., 2006). Zaniboni et al. (2006) utilizaram óleo de peixe na dieta de perus e foi observado aumento dos ácidos graxos n-3, isso resultou na redução da proporção de n-6/n-3 no esperma melhorando a viabilidade e a fertilidade, além disso efeitos positivos sobre a eclodibilidade e viabilidade do embrião. A comparação no uso de óleos de milho e salmão evidenciaram melhor taxa de fertilidade e redução da relação n-6: n-3 em galos alimentados com dieta com óleo de salmão (Blesbois et al., 1997).

Dietas de reprodutores com suplementação de ácidos graxos, alteram significativamente o processo de fertilização dos espermatozoides frescos, pois esses ácidos melhoram a motilidade e vitalidade dos espermatozoides. Além disso, melhorar a estrutura da membrana, a fluidez ou a suscetibilidade à peroxidação dos espermatozoides podem ser danificadas alterando fosfolipídios específicos (Blesbois et al., 1997).

Al-Daraji et al. (2010), observaram que a fertilidade e a eclodibilidade das codornas melhoraram ao incluir 3\% de óleo de peixe ou óleo de linhaça em comparação com o óleo de girassol. Esse efeito pode estar relacionado à proporção n-6: n3 mais estreita em óleos de peixes e óleo de linhaça do que no óleo de girassol. No entanto, nos estudos realizados, o efeito da fonte de ácido graxo foi determinado independentemente da proporção n-6: n-3.

\section{Considerações Finais}

Devido à escassez de trabalhos para matrizes de codornas se faz necessária a condução de mais pesquisas para evidenciar o impacto que a suplementação de n-3 na dieta para balancear a relação n-6: n-3 e seus efeitos sobre a composição da gema, incubação, eclodibilidade, fertilidade e efeitos sobre a progênie. Com destaque maior para codornas porque há poucos trabalhos na literatura, mesmo sendo uma área que vem crescendo a sua produção no Brasil. Desta forma, a inclusão de óleos vegetais como fontes de ômega 3 na ração de codornas japonesas, pode ser boa alternativa para ofertar ao mercado consumidor ovos fortificados com n-3, além de melhorar os parâmetros de reprodução, visto que possuem extrema importância na produção.

Os trabalhos realizados com relações ideais para galinhas poedeiras e matrizes de frango de corte já estão bem definidas, entretanto para codornas ainda são escassos nessa área, portanto são necessárias mais pesquisas utilizando relações n6:n3 para esta espécie, visando ajudar nas questões produtivas, reprodutivas e também na qualidade da progênie. 


\section{Referências}

Ahmad, S., Yousaf, M., Sabri, M. A. \& Kamran, Z. (2012). Response of laying hens to omega-3 fatty acids for performance and egg quality. Avian Biology Research, 5(1), 1-10.

Al-Daraji, H. J., Al-Mashada, H. A., Al-Hayani, W. K., Mirza, H. A. \& Al-Hassani, A. S. (2010). Effect of dietary supplementation with different oils on productive and reproductive performance of quail. International Journal of Poultry Science, 9(5), 429-435.

Andrade, P. M. M. \& Carmo, M. G. T. (2006). Ácidos graxos n-3: um link entre eicosanoides, inflamação e imunidade. Revista de Metabolismo e Nutrição, $8(3), 135-143$.

Baucells, M. D., Crespo, N., Barroeta, A. C., López-Ferrer, S. \& Grashorn, M. A. (2000). Incorporation of different polyunsaturated fatty acids into eggs. Poultry Science, 79, 51-59.

Bertipaglia, L. A., Sakamoto, M. I., Bertipaglia, L. M. A. \& Melo, Gm. P. (2016). Lipid sources in diets for egg-laying Japanese quail: performance and egg quality. Acta Scientiarum. Animal Sciences, 38, 281-284.

Blesbois, E., Lessire, M., Grasseau, I., Hallouis, J.M. \& Hermier. D. (1997). Effect of dietary fat on the fatty acid composition and fertilizing ability of fowl semen. Biology Reproductive, 56, 1216-1220.

Blesbois, E., Douard, V., Germain, M., Boniface, P. \& Pellet, F. (2004). Effects of n-3 polyunsaturated dietary supplementation on the reproductive capacity of male turkeys. Theriogenology, 61, 537-549.

Briz, R. C. (1997). Ovos com teores mais elevados de ácidos graxos Ômega 3. In: Simpósio técnico de produção de ovos, São Paulo. Anais... São Paulo: APA, p.153-193.

Bromfield, E. G., Aitken, R. J., Anderson, A. L., McLaughlin, E. A. \& Nixon,B.(2015). The impact of oxidative stress on chaperone-mediated human spermegg interaction. Human Reproduction, 30(11), 2597-2613.

Bruneel, C., Lemahieu, C., Fraeye, I., Ryckebosch, E., Buyse, J. \& Muylaert, K., Foubert, I. (2013) Impact of microalgal feed supplementation on omega-3 fatty acid enrichment of hen eggs. Journal of Functional Foods, 5(2), 897-904.

Burdge, G. C., Jones, A. E. \& Wootton, S. A. (2002). Eicosapentaenoic and docosapentaenoic acids are the principal products of $\alpha$-linolenic acid metabolism in young men. British Journal of Nutrition, 88(4), 355-363

Calder, P. C. (2006). N-3 Polyunsaturated fatty acids, inflammation, and inflammatory diseases. The American Journal of Clinical Nutrition, 83(6), 15051519 .

Caston, L. J., Squires, E. J. \& Leeson, S. (1994). Hen performance, egg quality, and the sensory evaluation of eggs from SCWL hens fed dietary flax. Canadian Journal of Animal Science, 74 (2), 347-353.

Cedro, T. M. M., Calixto, L. F. L., Gaspar, A. \& Hora, A. S. (2010). Teores de ácidos graxos em ovos comerciais convencionais e modificados com ômega-3. Revista Brasileira de Zootecnia, 39 (8), 1733-1739.

Cedro, T. M. M., Calixto, F. L. F., Gaspar, A. \& Agostinho, T. S. P. (2011). Proporções entre ácidos graxos poliinsaturados em ovos comerciais convencionais e enriquecidos com ômega-3. Ciência Rural, 41, 706-711.

Cerolini, S., Zaniboni, L., Maldjian, A. \& Gliozzi, T. (2006). Effect of docosahexaenoic acid and $\alpha$-tocopherol enrichment in chicken sperm on semen quality, sperm lipid composition and susceptibility to peroxidation. Theriogenology, 66(4), 877-886.

Cherian, G. \& Sim, J. (1992). Preferential accumulation of n-3 fatty acids in the brain of chicks from eggs enriched with n-3 fatty acids. Poultry Science, 71, $1658-1668$.

Cherian, G. \& Sim, J. (1993). Net transfer and incorporation of yolk n-3 fatty acids into developing chick embryos. Poultry Science, 72 , 98-105.

Cherian, G., Gopalakrishnan, N., Akiba, Y. \& Sim, J. (1997). Effect of maternal dietary n-3 fatty acids on the accretion of long-chain polyunsaturated fatty acids in the tissues of developing chick embryo. Neonatology, 72(3), 165-174.

Cherian, G., \& Sim, J. (2001). Maternal dietary $\alpha$-linolenic acid (18:3n-3) alters n-3 polyunsaturated fatty acid metabolism and liver enzyme activity in hatched chicks. Poultry Science, 80(7), 901-905.

Cherian, G. (2007). Metabolic and Cardiovascular Diseases in Poultry: role of dietary lipids. Poultry Science, 86 (5), $1012-1016$.

Cherian, G. (2008). Egg quality and yolk polyunsaturated fatty acid status in relation to broiler breeder hen age and dietary n-3 oils. Poultry Science, 87(6), 1131-1137.

Costa, F. A. D., Tavernari, F. C., Costa, O. A. D., Castro, F. F. \& Remus, A. (2017). Enriquecimento com ácidos graxos da série ômega 3 em carne de aves e ovos. PUBVET, 11(2), 113-123.

Dalle Zotte, A. \& Szendro, Z. (2011). The role of rabbit meat as functional food. Meat Science. 88(3), 319-331.

Dessimoni, T. K. A. S \& Aguiar, E. F. (2021). O uso da farinha de peixe na alimentação de poedeiras como fonte enriquecedora de ovos. Research Society and Development, $10(8), 1-8$.

Di Natale, C., Coclite, E., Di Ventura, L. \& Di Fabio, S. (2011). Fortification of maternal milk for preterm infants. The Journal of Maternal-Fetal \& Neonatal Medicine, 24, 41-43. 
El-Desoky, N. I., Hashem, N. M., Elkomy, A. \& Abo-elezz, Z. R. (2017). Physiological response and semen quality of rabbit bucks supplemented with Moringa leaves ethanolic extract during summer season. Animal, 11(9), 1549-1557.

Freitas, E. C., Nobrega, M. P., Troncom, F. R. \& Franco, G. S. (2012) Metabolismo Lipídico durante o exercício físico : mobilização do ácido graxo. Pensar a Prática, 15(3), 801-814. e20810817115.

Genchev, A. (2012). Quality and composition of japanese quail eggs (Coturnix japonica). Trakia Journal of Sciences, 10(2), 91-101.

Gonçalves, F. M, Santos, V. L., Contreira, C. L., Farina, G., Kreuz, B. S., Gentilini, F. P., Anciuti, M. A. \& Rutz, F. (2013). Nutrição in ovo: estratégia para nutrição de precisão em sistemas de produção avícola. Archivos de zootecnia, 62, 45-55.

Güçlü, B. K., Uyanđk, F. \& İşcan, K. M. (2008). Effects of dietary oil sources on egg quality, fatty acid composition of eggs and blood lipids in laying quail. South African Journal of Animal Science, 38, 91-100.

Jacobsen, C., Nielsen, N. S., Horn, A. F. \& Sørensen, A. M. (2013). Food Enrichment with Omega-3 Fatty Acids. Sawston: Woodhead Publishing, $464 f$.

Jiang, S., Cui, L. Y., Hou, J. F., Shi, C., Ke, X., Yang, L. C. \& Ma, X. P. (2014). Effects of age and dietary soybean oil level on eggshell quality, bone strength and blood biochemistry in laying hens. British Poultry Science, 55(5), 653-661.

Kayang, B. B., Fillon, V., Inoue-Murayama, M., Miwa, M., Leroux, S., Fève, K., Monvoisin, J., Pitel, F., Vignoles, M. \& Mouilhayrat, C. (2006). Integrated maps in quail (Coturnix japonica) confirm the high degree of synteny conservation with chicken (Gallus gallus) despite 35 million years of divergence. BioMed Central Genomics, 7, 1-18.

Khatibjoo, A., Kermanshahi, H., Golian, A. \& Zaghari, M. (2018). The effect of n-6/n-3 fatty acid ratios on broiler breeder performance, hatchability, fatty acid profile and reproduction. Journal of Animal Physiology and Animal Nutrition, 102, 986-998.

Koppenol, A., Buyse, J., Everaert, N., Willems, E., Wang, Y., Franssens, L. \& Delezie, E. (2014). Transition of maternal dietary n-3 fatty acids from the yolk to the liver of broiler breeder progeny via the residual yolk sac. Poultry Science, 94, 43-52.

Koppenol, A., Delezie, E., Wang, Y., Franssens, L., Willems, E., Ampe, B., Buyse, J. \& Everaert, N. (2015). Effects of maternal dietary EPA and DHA supplementation and breeder age on embryonic and post-hatch performance of broiler offspring. Journal of Animal Physiology and Animal Nutrition, 99, 3647.

Latour, M. A., Peebles, E. D., Boyle, C. R., Brake, J. D. \& Kellogg, T. F. (1995). Changes in serum lipid, lipoprotein and corticosterone concentrations during neonatal chick development. Neonatology, 67, 381-386.

Leeson, S. \& Summers, J. D. (2001). Scott's nutrition of the chicken. 4. ed. Canadá: University Books. 608 p.

Lehninger, A. L., Nelson, D. L. \& Cox, M. M. (2014). Princípios de Bioquímica. 6.ed. São Paulo: Sarvier.

Lemahieu, C., Bruneel, C., Ryckebosch, E., Muylaert, K., Buyse, J. \& Foubert, I. (2015) Impact of different omega-3 polyunsaturated fatty acid (n-3 PUFA) sources (flaxseed, Isochrysis galbana, fish oil and DHA Gold) on n-3 LC-PUFA enrichment (efficiency) in the egg yolk. Journal of Functional Foods, 19 , 8281-8287.

Liang, K., Zu, H., Xiaohong, W. (2020). Effect of storage on n-3 PUFA - enriched eggs. Cyta - Journal of Food 18 (1): $102-107$

Lima, D. G., Padovani, R. M., Amaya, D. B. R., Farfan, J. A., Nonato, C. T., Lima, M. T., Salay, E., Colugnati, F. A. B. \& Galeazzi, M. A. M. (2011). Tabela brasileira de composição de alimentos / Nepa. UNICAMP. 4. ed.- Campinas: NEPA- UNICAMP.

Luu, N. T., Madden, J., Calder, P. C., Grimble, R. F., Shearman, C. P., Chan, T., Dastur, N., Howell, W. M., Rainger, G. E. \& Nash, G. B. (2007). Dietary supplementation with fish oil modifies the ability of human monocytes to induce an inflammatory response. The Journal of Nutrition, 137 (12), $2769-2774$.

Manzke, N. E., Gomes, B. K., Lima, G. J. M. M. \& Xavier, E. G. (2016). Nutrição de leitões neonatos: importância da suplementação. Archivos de zootecnia, 65(252), 585- 591.

Martin, C. A., Almeida, V. V., Ruiz, M. R., Visentainer, J. E. L., Matshushita, M., Souza, N. E. \& Visentainer, J. V. (2006). Ácidos graxos poliinsaturados ômega-3 e ômega-6: importância e ocorrência em alimentos. Revista de Nutrição, 19(6), 761-770.

Medeiros, F. M. \& Alves, M. G. M. (2014). Qualidade de ovos comerciais. Nutritime, 11(4), 3515-3524.

Missão, M. R. (2006). SOJA: origem, classificação, utilização e uma visão abrangente do mercado. Maringá Management: Revista de Ciências Empresariais, $7-15$.

Neves, M. M. \& Henry, M. (2012). Gema do ovo de galinha e a ação protetora de suas lipoproteínas de baixa densidade na criopreservação do sêmen: uma revisão. Revista Brasileira Reprodução Animal, 36(4), 209-214.

Nimpf, J. \& Schneider, W. J. (1991). Receptor-mediated lipoprotein transport in laying hens. The Journal of Nutrition. 121(9), 1471-1474.

Noble, R. C., Speake, B. K., Mccartney, R., Foggin, C. M. \& Deeming, D. C. (1996). Yolk lipids and their fatty acids in the wild and captive ostrich (Struthio camelus). Comparative Biochemistry and Physiology Part B: Biochemistry and Molecular Biology, 113(4), 753-756.

Oliveira, D. D., Baião, N. C., Cançado, S. V., Grimaldi, R., Souza, M. R., Lara, L. J. C. \&Lana, A. M. Q. (2010) Effects of lipid sources in the diet of laying hens on the fatty acid profiles of egg yolks. Poultry Science, 89(11), 2484-2490.

Oliveira, D. D., Baião, N. C., Cançado, S. V., Oliveira, B. L., Lana, Â. M. Q. \& Figueiredo, T. C. (2011). Effects of the use of soybean oil and animal fat in the diet of laying hens on production performance and egg quality. Ciência e Agrotecnologia, 35, 995-1001. 
Pastore, S. M., Oliveira, W. P. \& Muniz, J. C. L. Panorama da coturnicultura no Brasil. Nutritime,9,2041-2049.

Pereira, A. S., Shitsuka, D. M., Pereira, F. J. \& Shitsuka, R. (2018). Metodologia da Pesquisa Científica. 1.ed. Santa Maria: Universidade Federal de Santa Maria. 119p.

Perini, J. A. L., Stevanato, F. B., Sargi, S. C., Visentainer, J. E. L., Dalalio, M. M. O., Matshushita, M., Souza, N. E. \& Visentainer, J.V. (2010). Ácidos graxos poli-insaturados n-3 e n-6: metabolismo em mamíferos e resposta imune. Revista de Nutrição, 23(6), 1075-1086.

Phetteplace, H. W. \& Watkins, B. A. (1990). Lipid measurements in chickens fed different combinations of chicken fat and menhaden oil. Journal of Agricultural and Food Chemistry, 38(9), 1848-1853.

Petrović, M., Gačić, M., Karačić, V., Gottstein, Ž., Mazija, H \& Medić, H. (2012). Enrichment of eggs in n-3 polyunsaturated fatty acids by feeding hens with different amount of linseed oil in diet. Food Chemistry, 135, 1563-1568.

Ribeiro, B. R. C., Lara, L. J. C., Baião, N. C., Lopez, C. A. A., Fiuza, M. A., Cançado, S. V. \& Silva, G. M. M. (2007). Efeito do nível de ácido linoleico na ração de matrizes pesadas sobre o peso, composição e eclosão dos ovos. Arquivo Brasileiro de Medicina Veterinária e Zootecnia, $59,789-796$.

Rostagno, H. S., Albino, L. F. T., Donzele, J. L., Gomes, P. C., Oliveira, R., Lopes, D. C. \& Euclides, R. F. (2017). Composição de alimentos e exigências nutricionais (3ed. Vol. 1). Viçosa: Universidade Federal de Viçosa.

Saber, S. N. \& Kutlu, H. R. (2020). Effect of including n-3/n-6 fatty acid feed sources in diet on fertility and hatchability of broiler breeders and post-hatch performance and carcass parameters of progeny. Journal of Animal Science, 33(2), 305-312.

Saini, R. K. \& Keum, Y. S. (2018). Omega-3 and omega-6 polyunsaturated fatty acids: Dietary sources, metabolism, and significance - A review. Life Sciences, 203, 255-267.

Santillo, A., Caroprese, M., Marino, R., Sevi, A. \& Albenzio, M. (2016). Quality of buffalo milk as affected by dietary protein level and flaxseed supplementation. Journal of Dairy Science, 99(10), 7725-7732.

Santos, N. W., Yoshimura, E. H., Machado, E., Pintro, P. T. M., Montanher, P. F., Visentainer, J. V. \& Santos, G. T., Zeoula, L. M. (2016). Antioxidant effects of a propolis extract and vitamin E in blood and milk of dairy cows fed diet containing flaxseed oil. Livestock Science, 191, $132-138$.

Santos, R. D., Gagliardi, A. C. M., Xavier H. T., Magnoni, C. D., Cassani, R., Lottenberg, A. M. P., Casella Filho, A., Araújo, D. B., Cesena, F. Y., Alves, R. J., Fenelon, G., Nishioka, S. A. D., Faludi, A. A., Geloneze B., Scherr, C., Kovacs, C., Tomazzela, C., Carla, C., Barrera-Arellano, D., Cintra, D., Quintão, E., Nakandakare, E. R., Fonseca, F. A. H., Pimentel, I., Santos, J. E., Bertolami, M. C, Rogero, M., Izar, M. C., Nakasato, M., Damasceno, N. R. T., Maranhão, R., Cassani, R. S. L., Perim, R. \& Ramos, S. (2013). I DIRETRIZ SOBRE O CONSUMO DE GORDURAS E SAÚDE CARDIOVASCULAR. Arquivos Brasileiros De Cardiologia. p.48.

Scottá, B. A, Campos,P. F, Gomide,A. P. C., Barroca,C. C., Formigoni, A. S. \& Zerlotini, M. F. (2014). Nutrição pré e pós-eclosão em aves. PUBVET, 8(8),116.

Simopoulos, A. P. (2002). Omega-3 fatty acids in wild plants, nuts and seeds. Asia Pacific Journal of Clinical Nutrition, 11,163-173.

Simopoulos, A. P. (2004). Omega-6/Omega-3 Essential Fatty Acid Ratio and Chronic Diseases. Food Reviews International, 20(1), 77-90.

Speake, B. K., Murray, A. M. B. \& Noble, R. C. (1998). Transport and transformations of yolk lipids during development of the avian embryo. Progress in Lipid Research, 37(1), 1-32.

Sprecher, H. (2000). Metabolism of highly unsaturated n-3 and n-6 fatty acids. Biochimica et Biophysica Acta (Bba) - Molecular and Cell Biology of Lipids, $1486(3), 219-231$

Stefanello, F. P. S., Pasqualotti, A. \& Pichler, N. A. (2019). Análise do consumo de alimentos fontes de ômega 3 por participantes de grupos de convivências. Revista Brasileira Geriatria e Gerontologia, 22(6):1-9.

Tunsaringkarn, T., Tungjaroenchai, W. \& Siriwong, W. (2013). Nutrient benefits of quail (Coturnix japonica) eggs. Journal of Scientific and Research Publications, 3(5), 1-8.

Vaz, D. S. S., Guerra, F. M. R. M., Gomes, C. F., Simão, A. N. C. \& Junior, J. M. (2014). A importância do ômega 3 para a saúde humana: um estudo de revisão. Revista UNINGÁ, 20(2), 48-54.

Walzem, R. L., Hansen, R. J., Wiliams, D. L \& Hamilton, R. L. (1999). Estrogen induction of VLDLy assembly in egg-laying hens. Journal of Nutrition, Bethesda, 129, 467-472.

Youdim, K. A., Martin, A. \& Joseph, J. A. (2000). Essential fatty acids and the brain: possible health implications. International Journal of Developmental Neuroscience, 18(5), 383-399.

Zaniboni, L., Rizzi, R. \& Cerolini, S. (2006). Combined effect of DHA and $\alpha$-tocopherol enrichment on sperm quality and fertility in the turkey. Theriogenology, 65, 1813-1827. 